\title{
Myrrh and artesunate modulate some Th1 and Th2 cytokines secretion in Schistosoma mansoni infected mice
}

\author{
KADRY A. ELBAKRY', MOHAMED M. ABDELAZIZ2 \\ ${ }^{1}$ Zoology Department, Faculty of Science, Damietta University, Damietta, Egypt \\ ${ }^{2}$ Gastroenterology Center, Mansoura University, Mansoura, Egypt
}

\begin{abstract}
The effects of artesunate and myrrh on S. mansoni infection and the levels of some Th1 and Th2 cytokines were evaluated in the present study. Six weeks after infection, a group of mice was treated with $4 \mathrm{mg} / \mathrm{kg}$ of artesunate and other group was treated with $10 \mathrm{mg} / \mathrm{kg}$ of myrrh for 3 successive days. Worm burden was reduced with a percentage of $53.7 \%$ and $58.78 \%$ after treatment with myrrh and artesunate respectively as well as the levels of $\mathrm{Ig} G$ antibodies were significantly reduced compared with infected group. No obvious changes were observed in the level of interferon $\gamma$ after treatment. After treatment with artesunate, interleukin 2 (IL-2) level was significantly decreased, while no significant difference was observed in myrrh-treated group compared with the infected group. On the other hand, the level of IL-10 was not significantly decreased after treatment with artesunate, but it was significantly increased after treatment with myrrh. However, IL-12 levels were significantly decreased after treatment with artesunate. The results demonstrated that, artesunate or myrrh treatment could give a level of protection against $S$. mansoni infection and modulate the levels of some Th1 and Th2 cytokines in mice infected with S. mansoni.
\end{abstract}

Key words: cytokine, Schistosoma infection, myrrh and artesunate.

(Cent Eur J Immunol 2016; 41 (2): 138-142)

\section{Introduction}

Schistosomiasis is caused by the platyhelminth worms of the genus Schistosoma, trematodes that live in the bloodstream of humans and animals [1]. Myrrh is a successful product extracted from the stem of Commiphora molmol plant [2], and affect schistosome's musculature, leading to uncoupling of male and female worms and their extravasation to the liver tissue [3]. The Egyptian Ministry of Health licensed myrrh under the name of Mirazid for human use against Schistosoma species. However, conflicting reports on its efficacy were published about the usefulness of its use as a novel therapy for schistosomiasis $[3,4]$.

Artesunate is widely used as an antimalarial drug and has been found to be effective against $S$. japonicum, S. mansoni, and Fasciola hepatica [5]. A single oral injection of $400 \mathrm{mg} / \mathrm{kg}$ of an artemether to mice infected with approximately 80 cercariae of $S$. mansoni at the pre-patent and patent period led to $71-81 \%$ reduction in total worm burden $[6,7]$.

Some independent evidence has linked the high liver pathology of infected mice to the persistence of a pro-in- flammatory state marked by the increase in Th1-type cytokines such as interleukin (IL)-2, interferon $\gamma$ (IFN- $\gamma$ ) and tumor necrosis factor $\alpha$ (TNF- $\alpha$ ) and the deficiency of anti-inflammatory Th2-type cytokines such as IL-4 and IL-10 or both [8]. Interleukin 12 secreted from Th1 plays an essential role in bridging the innate and adaptive arms of immunity, in regulating inflammatory responses, innate resistance to infection, and adaptive immunity [9]. Interleukin 10 , IL-12p40, and IL-13R $\alpha 2$ act cooperatively to suppress liver fibrosis in mice following the infection with $S$. mansoni. This model rapidly reproduces many of the complications observed in patients with advanced cirrhosis, so it might be used to evaluate the efficacy of anti-fibrotic reagents being developed for schistosomiasis or other fibrotic diseases associated with a T-helper 2 cell-mediated immune response [10]. Interleukin 10 is a cytokine produced by both $\mathrm{T}$ cell and non- $\mathrm{T}$ cell sources during schistosome infection [11] and has been shown to inhibit the priming of Th1 responses by dendritic cells [12]. Also pre-patent schistosome infection was associated with a significant decrease in the baseline expression of IL-12, a critical stimulator of $\mathrm{T}$ cell proliferation and IFN- $\gamma$ pro-

Correspondence: Kadry A. Elbakry, Zoology Department, Faculty of Science, Damietta University, 34518 New Damietta City, Egypt,

e-mail: kelbakry2003@yahoo.com

Submitted: 17.12.2015, Accepted: 10.02.2016 
duction [13]. The aim of the present study is to evaluate the effects of myrrh and artesunate treatment on S. mansoni worms and the level of some Th1 and Th2 cytokines in mice infected with S. mansoni.

\section{Material and methods}

The present study includes 30 Outbred Swiss albino female mice (about $20 \mathrm{~g}$ in weight) infected intraperitoneally (i.p) with 150 cercariae of $S$. mansoni (Egyptian strain) as well as 10 non-infected females. Mice were purchased from Theodore Bilhars Institute, Giza, Egypt and housed in the animal house, Zoology Department, Faculty of Science, Damietta University at $25 \pm 2^{\circ} \mathrm{C}$ temperature, about $60 \%$ relative humidity and $12 \mathrm{~h}$ photoperiod. They had access to standard mice feed and water. Mice received humane care during treatments in compliance with the approval of the ethics committee of Damietta University, Damietta, Egypt.

\section{Experimental design}

Mice were divided into 4 groups, 10 mice each. Normal control: non-infected, non-treated group. Infected control: infected with 150 cercariae of S. mansoni. Artesunate group: infected and after 6 weeks of infection, mice were treated orally with $4 \mathrm{mg} / \mathrm{kg}$ bw of artesunate (Guilin Pharmaceuticals, Hong Kong) for 3 consecutive days. Myrrh group: infected and after 6 weeks, mice were treated orally with $10 \mathrm{mg} / \mathrm{kg}$ bw of myrrh extract (kindly provided by Prof Dr. Gamal A. Badra, National Liver Institute, Minufiya University) for 3 consecutive days. Two weeks after the last dose of treatment, blood samples were collected, sera from all groups were prepared and stored at $-20^{\circ} \mathrm{C}$ until used, then mice were perfused to recover the adult worms.

\section{Adult Worm Recovery}

Two weeks after the last dose of treatment, worms were recovered from the portal system and mesenteric veins by vascular perfusion technique [14]. The perfused saline $(0.85 \%$ sodium chloride $+0.75 \%$ sodium citrate $)$ plus blood drained through the portal vein was recovered in a beaker, and left to sediment. The supernatant was discharged and the sediment washed out twice with saline. After washing, the recovered worms were counted under a dissecting microscope.

\section{Determination of antischistosomal antibodies}

An amount of $25 \mathrm{mg} / \mathrm{ml}$ of schistosome antigenic preparation (SWAP) (purchased from Theodore Bilhars Institute, Cairo, Egypt) was added to 96-well microtiter plate $(50 \mathrm{ml} /$ well) and incubated overnight at room temperature. The non-specific proteins were blocked by adding nonfat milk for 30 minutes. Sera from treated and non-treated mice diluted in PBS-T20 were added $(50 \mathrm{ml} /$ well $)$ and incubated at $37^{\circ} \mathrm{C}$ for $2 \mathrm{~h}$. Then the plate was washed with PBS-T20. To each well, $50 \mathrm{ml}$ of goat anti-mouse IgG (alkaline phosphatase labeled) conjugate (Sigma, USA) diluted $1: 500$ in non-fat dry milk were added and incubated at $37^{\circ} \mathrm{C}$ for $1 \mathrm{~h}$. After washing, $1 \mathrm{mg} / \mathrm{ml}$ of P-nitrophenyl phosphate substrate (Sigma) was added for $30 \mathrm{~min}$. The reaction was stopped using $0.16 \mathrm{M}$ sulphuric acid and the optical density (OD) of each well then read at $405 \mathrm{~nm}$ using micro plate reader (BioTek Instruments, Vermont, USA). The level of antibodies was expressed as OD [15].

\section{Determination of serum interferon $\gamma$ and interleukin 2}

A polystyrene flat bottom microtiter plate was coated overnight with $50 \mu \mathrm{l} /$ well of treated and non-treated diluted mice sera $(1: 100)$ in carbonate / bicarbonate buffer $(\mathrm{pH}$ 9.6). After blocking with non-fat dry milk, rat anti-mouse IFN- $\gamma$ mAb (Sigma, USA) and goat anti-mouse IL-2 mAb (Sigma, USA) diluted 1 : 1000 in PBS, PH 7.2 has added and the plate was incubated at $37^{\circ} \mathrm{C}$ for $1 \mathrm{~h}$. After washing, $50 \mu \mathrm{l} /$ well of goat anti-rat IgG alkaline phosphatase conjugate (for IFN- $\gamma$ ) (Sigma, USA) and rabbit anti-goat IgG alkaline phosphatase conjugate for IL-2 (Sigma, USA) diluted $1: 600$ in PBS-T20 were added at room temperature for $2 \mathrm{~h}$. After washing, $1 \mathrm{mg} / \mathrm{ml}$ of P-nitrophenyl phosphate substrate (Sigma) was added for $30 \mathrm{~min}$. The reaction was stopped using 0.16 M sulphuric acid and the OD of each well then read at $405 \mathrm{~nm}$ using micro plate reader (BioTek Instruments, Vermont, USA).

\section{Determination of serum levels of interleukin 12 and interleukin 10}

Serum of each mouse from all groups was diluted $1: 100$ in carbonate/bicarbonate buffer ( $\mathrm{pH} 9.6$ ). A volume of $50 \mu$ of diluted serum was added to each well of 96-well microtiter plate overnight. After blocking non-specific proteins, goat anti-mouse IL-12 and IL-10 monoclonal antibodies (Sigma Company) diluted $1: 1000$ in PBS, pH 7.2 has added at $37^{\circ} \mathrm{C}$ for one hour. The plate washed with PBS-T20 and then $50 \mu 1$ of rabbit anti-goat IgG alkaline phosphatase (Sigma) conjugate (diluted $1: 600$ in PBS-T20) was added to each well at room temperature for 2 hours. After washing, $1 \mathrm{mg} / \mathrm{ml}$ of P-nitrophenyl phosphate substrate (Sigma) was added for $30 \mathrm{~min}$. The reaction was stopped using $0.16 \mathrm{M}$ sulphuric acid and the OD of each well was then read at $405 \mathrm{~nm}$ using micro plate reader (BioTek Instruments, Vermont, USA).

\section{Statistical analysis}

Student $t$-test was performed using the statistical program package, instate software, version 2.03 (Graphpad, 
Table 1. Worm burden and the percent of male and female worms in experimental groups

\begin{tabular}{|c|c|c|c|c|}
\hline Groups & Worm burden ${ }^{\mathfrak{x}}$ & $\%$ reduction & $\%$ ô worms & $\%$ \% worms \\
\hline Infected & $14.80 \pm 9.30$ & & 47.98 & 52.02 \\
\hline Artesunate & $6.10 \pm 3.09^{*}$ & 58.78 & 53.70 & 46.30 \\
\hline Myrrh & $6.85 \pm 2.90^{*}$ & 53.70 & 56.20 & 43.80 \\
\hline
\end{tabular}

Table 2. The OD of antischistosomal IgM and IgG antibodies in experimental groups

\begin{tabular}{lcc}
\hline Groups & $\mathbf{I g M}^{\mathbf{f}}$ & $\mathbf{I g G}^{\mathbf{\varepsilon}}$ \\
\hline Normal & $0.05 \pm 0.01$ & $0.18 \pm 0.03$ \\
\hline Infected & $0.30 \pm 0.04^{*}$ & $0.73 \pm 0.08^{*}$ \\
\hline Artesunate & $0.20 \pm 0.01^{*}$ & $0.60 \pm 0.05^{*}$ \\
\hline Myrrh & $0.21 \pm 0.01^{*}$ & $0.56 \pm 0.01^{*}$ \\
\hline $\begin{array}{l}\text { E Data are expressed as mean } \pm \text { standard deviation } \\
* \text { Significant compared with the normal control }\end{array}$ \\
* Significant compared with the infected group
\end{tabular}

USA) and on IBM PCIAT compatible computer. The data were considered significant at $p<0.05$.

\section{Results}

\section{Worm burden}

Table 1 indicates the worm recovered from mice infected with 150 cercariae of $S$. mansoni and treated with artesunate and myrrh. The worm recovered after treatment with artesunate and myrrh was significantly reduced $(p<0.05)$ with a percentage of reduction $58.7 \%$ and $53.7 \%$, respectively. In addition, the percentage of recovered female worms was lower than that of the male worms after treatments with artesunate and myrrh (Table 1).

\section{Antischistosomal antibodies}

The level of antischistosomal IgG antibodies was significantly decreased in both of artesunate-treated group and myrrh-treated group, while no significant differences in both treated groups were observed in the levels of antischistosomal $\operatorname{IgM}$ antibodies compared with infected group as shown in Table 2.

\section{Th1 and Th2 cytokines}

As shown in Table 3, the level of IFN- $\gamma$ was not changed significantly after treatment with myrrh or artesunate. On the other hand, the levels of both IL-2 and IL-12 were significantly decreased in artesunate-treated group compared with infected group. The levels of these cytokines were also decreased in myrrh-treated group but the difference was not significant. The level of IL-10 was not significantly decreased after treatment with artesunate, while it was significantly increased after treatment with myrrh.

\section{Discussion}

Schistosomiasis is one of the major endemic parasitic diseases in the world. Schistosoma mansoni, S. haematobium, and $S$. japonicum are the species of major medical relevance to humans [16]. Myrrh (commercially known as Mirazid) is used as a new antischistosomal drug in Egypt, but results about its antischistosomal activities are controversial [17-21]. The present study showed that treatment with a myrrh extract and artesunate resulted in the reduction of worm burden by $58.7 \%$ and $53 \%$, respectively. In addition, the levels of antischistosomal antibodies were also reduced. In addition, the percentage of female worms was reduced by both treatments. This may be a mechanism for the reduction of liver pathology because the eggs laid by female worms are the main cause of the liver pathology and the fatal outcome. However, Lotfy et al. [22] concluded that Mirazid showed some schistosomicidal effects against murine $S$. mansoni. However, it was not efficient enough to cure any of the studied mice.

Cytokines are important regulators of immune inflammatory responses and play a major role in the regulation of collagen fiber deposition and degradation [23].

Table 3. The OD of IFN- $\gamma$, IL-2, IL-10 and IL-12 in experimental groups

\begin{tabular}{lcccc}
\hline Groups & IFN- $\gamma$ & IL-2 & IL-12 & IL-10 \\
\hline Normal & $0.15 \pm 0.10$ & $0.23 \pm 0.12$ & $0.29 \pm 0.08$ & $0.29 \pm 0.09$ \\
\hline Infected & $0.11 \pm 0.03$ & $0.80 \pm 0.17$ & $0.68 \pm 0.17$ & $0.59 \pm 0.12$ \\
\hline Artesunate & $0.10 \pm 0.02$ & $0.50 \pm 0.08^{*}$ & $0.52 \pm 0.03 *$ & $0.53 \pm 0.10$ \\
\hline Myrrh & $0.11 \pm 0.05$ & $0.70 \pm 0.14 \dagger$ & $0.60 \pm 0.23$ & $0.80 \pm 0.02 * \dagger$ \\
\hline
\end{tabular}

Data are expressed as mean \pm standard deviation

* Significant compared with the infected control group

$\dagger$ Significant compared with the artesunate group 
Several independent evidences have referred the high pathology to the persistence of a pro-inflammatory state marked by the increase in Th1-type cytokines such as IFN- $\gamma$ and TNF- $\alpha$ and Th2-type cytokines [24].

The present study showed that, no changes were observed in the level of IFN- $\gamma$ in mice infected with S. mansoni after treatment with myrrh or artesunate, while the level of IL-12 was significantly decreased after treatment with artesunate and was not significantly decreased after treatment with myrrh. On the other hand, the levels of Th1-cytokines especially IL-2 were increased after infection with S. mansoni, while after treatment with artesunate the level of IL-2 was significantly reduced compared with the infected group. Furthermore, the level of IL-2 was also reduced in myrrh-treated group but the difference was not significant. Thus, the reduced levels of IL-2 in the present study as an inflammatory cytokines can reduce the pathology in the treated mice as reported in other previous studies $[10,25,26]$.

In human schistosomiasis, IL-10 plays a key role in downregulating both Th1 and Th2 responses to schistosome antigens, and hence limiting the extent of pathology [27]. The present study clearly showed that the reduced anti-inflammatory IL-10 levels in the infected group were accompanied with the elevated level of inflammatory IL-2 cytokine. After treatment with myrrh, the levels of IL-10 were increased and this increase was accompanied with the reduction in the level of IL-2. It has been found that liver egg granulomas in $S$. mansoni infected mice are controlled by both type 1 cytokines, IL-2, IL-12, IFN- $\gamma$ and type 2 cytokines, IL-4, IL-5, IL-10 and IL-13 [28, 29]. A pivotal role of IL-10 in downregulating both Th1 and Th2 responses to schistosome Ags, and hence limiting the extent of pathology, has also been demonstrated [27].

In BL/6 mice there is an initial Th1-polarized proinflammatory response, marked by IFN- $\gamma$, which following parasite oviposition at $5 \mathrm{wk}$ of infection, is gradually replaced by a Th2-dominated environment characterized by the rise of IL-4, IL-5, IL-10 and IL-13. The Th1 to Th2 cytokine switch is critical for the modulation of immunopathology [30].

Moreover, it was shown that the ratio of IFN- $\gamma-$ IL-10 influences the levels of TNF- $\alpha$. Given that IFN- $\gamma$ has been specifically associated with protection against fibrosis $[31,32]$ and that its production depends on the relative concentration of IL-10, it is conceivable that IL-10 might also play some role in the development of morbidity in schistosomiasis. Furthermore, other cytokines, including IL-13, have already been reported to be involved in the development of periportal fibrosis in patients with chronic schistosomiasis living in areas of endemicity [33].

Mice deficient in IL-10 were associated specifically with an increased risk of hepatic fibrosis, while others have shown that IL-10 is important in reducing the pathology of acute schistosomiasis and that the level of IL-10 decreases in patients with hepatosplenomegaly [34]. In conclusion, the present study revealed that myrrh and artesunate treatment can modulate the levels of Th1 and Th2 cytokines during S. mansoni infection.

\section{The authors declare no conflict of interests.}

\section{References}

1. El Ridi RAF, Tallima H (2013): Novel therapeutic and prevention approaches for schistosomiasis. J Adv Res 4: 467-478.

2. Tonkal AM, Morsy TA (2008): An update review on Commiphora molmol and related species. J Egypt Soc Parasitol 38: 763-796.

3. Badria F, Abou-Mohamad G, El-Mowafi A, et al. (2001): Mirazid: a new schistosomicidal drug. Pharma Biol 39: 127131.

4. Osman MM, El-Taweel HA, Shehab AY, Farag HF (2010): Ineffectiveness of myrrh-derivative Mirazid against schistosomiasis and fascioliasis in humans. East Mediterr Health $\mathbf{J}$ 16: 932-936.

5. Fathy FM (2011): Anthelmintic effect of artesunate in experimental heterophyid infection. J Egypt Soc Parasitol 41: 469483.

6. Xiao SH, Catto BA (1989): In vitro and in vivo studies of the effect of artemether on Schistosoma mansoni. Antimicrob Agents Chemother 33: 1557-1562.

7. Abdul-Ghani R, Loutfi N, Sheta M, Hassan A (2011): Artemether shows promising female schistosomicidal and ovicidal effects on the Egyptian strain of Schistosoma mansoni after maturity of infection. Parasitol Res 108: 1199-1205.

8. Rutitzky LI, Hernandez HJ, Yim YS, et al. (2005): Enhanced egg-induced immunopathology correlates with high IFN-gamma in murine schistosomiasis: identification of two epistatic genetic intervals. J Immunol 174: 435-440.

9. Salem ML, Shoukry NM, Zidan AA, Vournakis J (2014): Immunomodulatory effects of IL-12 released from poly- $N$-acetyl glucosamine gel matrix during schistosomiasis infection. Cytotechnology 66: 667-675.

10. Margaret M, Kane M, Cheever A, et al. (2014): Accelerated, Progressive, and Lethal Liver Fibrosis in Mice that Lack Interleukin (IL)-10, IL-12p40, and IL-13R $\alpha 2$. Gastroenterol 2014; 141: 2200-2209.

11. Hesse M, Piccirillo CA, Belkaid Y, et al. (2004): The pathogenesis of schistosomiasis is controlled by cooperating IL-10-producing innate effector and regulatory T cells. J Immunol 172: 3157-3166.

12. McKee AS, Pearce EJ (2004): CD25+CD4+ cells contribute to $\mathrm{Th} 2$ polarization during helminth infection by suppressing Th1 response development. J Immunol 2004; 173: 1224-1231.

13. Kane CM, Cervi L, Sun J, et al. (2004): Helminth antigens modulate TLR-initiated dendritic cell activation. J Immunol 173: 7454-7461.

14. Duvall RH, DeWitt WB (1967): An improved perfusion technique for recovering adult schistosomes from laboratory animals. Am J Trop Med Hyg 16: 483-486.

15. Attalah AM, Abdel Aziz M, Abbas AT, et al. (2004): Vaccination of mice with a $30 \mathrm{kDa}$ Schistosoma antigen with and without adjuvant induces high protection against S. mansoni infection. J Helminthol 2004; 78: 189-194. 
16. King CH, Dickman K, Tisch DJ (2003): Reassessment of the cost of chronic schistosome infection in sub-Saharan Africa. Acta Trop 86: 125-139.

17. Soliman OE, EL-Arman M, Abdul-Samie ER, et al. (2004): Evaluation of myrrh (Mirazid) therapy in fascioliasis and intestinal schistosomiasis in children: immunological and parasitological study. J Egypt Soc Parasitol 34: 941-966.

18. ABO-Madyan AA, Morsy TA, Motawea SM (2004): Efficacy of myrrh in the treatment of Schistosomiasis (haematobium and mansoni) in Ezbet El-Bakly, Tamyia Center, El-Fayoum Governorate. Egypt J Egypt Soc Parasitol 34: 423-426.

19. Botros S, William S, Ebeid F, et al. (2004): Lack of evidence for an antischistosomal activity of myrrh in experimental animals. Am J Trop Hyg 71: 206-210.

20. Barakat R, EL-Morshedy H, Fenwick A (2005): Efficacy of myrrh in the treatment of human schistosomiasis mansoni. Am J Trop Med Hyg 73: 365-367.

21. Abdel-Aziz M, Abbas AT, Elbakry KA, et al. (2006): Immune response on mice infected with Schistosoma mansoni and treated with myrrh. J Med Sci 6: 858-861.

22. Lotfy WM, Nageh AM, Hussein NA, Hassan AA (2013): Application and evaluation of a molecular approach for detection of the schistosomicidal effect of Mirazid ${ }^{\circledR}$ (myrrh) in the murine model. J Adv Res 4: 563-567.

23. Vaillant B, Chiaramonte MG, Cheever AW, et al. (2001): Regulation of hepatic fibrosis and extracellular matrix genes by the th response: new insight into the role of tissue inhibitors of matrix metalloproteinases. J Immunol 167: 7017-7026.

24. Hoffmann KF, Wynn TA, Dunne DW. Cytokine-mediated host responses during schistosome infections; walking the fine line between immunological control and immunopathology. Adv Parasitol 2002; 52: 265-307.

25. Rutitzky LI, Hernandez HJ, Stadecker MJ (2001): Th1-polarizing immunization with egg antigens correlates with severe exacerbation of immunopathology and death in schistosome infection. Proc Natl Acad Sci 98: 13243-1328.

26. Rutitzky LI, Mirkin GA, Stadecker MJ (2003): Apoptosis by neglect of CD4+ Th cells in granulomas: a novel effector mechanism involved in the control of egg-induced immunopathology in murine schistosomiasis. J Immunol 171: 18591867.

27. Hoffmann KF, Cheever AW, Wynn TA (2000): IL-10 and the dangers of immune polarization: excessive type 1 and type 2 cytokine responses induce distinct forms of lethal immunopathology in murine schistosomiasis. Immunol 164: 6406.

28. Leptak CL, McKerrow JH (1997): Schistosome egg granulomas and hepatic expression of TNF-alpha are dependent on immune priming during parasite maturation. J Immunol 158: 301-307.

29. Wynn TA, Cheever A, Williams M, et al. (1998): IL-10 regulates liver pathology in acute murine Schistosomiasis mansoni but is not required for immune down-modulation of chronic disease. J Immunol 1998; 160: 4473.

30. Iacomini J, Ricklan D, Stadecker M (1995): T cells expressing the gd $\mathrm{T}$ cell receptor are not required for egg granuloma formation in schistosomiasis. Eur J Immunol 25: 884-888.

31. Henri S, Chevillard C, Mergani A, et al. (2002): Cytokine regulation of periportal fibrosis in humans infected with Schistosoma mansoni: IFN-gamma is associated with protection against fibrosis and TNF-alpha with aggravation of disease. J Immunol 169: 929-936.

32. Booth M, Mwatha JK, Joseph S, et al. (2004): Periportal fibrosis inhuman Schistosoma mansoni infection is associated with low IL-10, lowIFN- $\gamma$, high TNF $\alpha$, or low rantes, depending on age and gender. J Immunol 172: 1295-1203.

33. Ribeiro de Jesus, A, Magalhaes A, Miranda DG, et al. (2004): Association of type 2 cytokines with hepatic fibrosis inhuman Schistosoma mansoni infection. Infect Immun 72: 3391-3397. 34. Montenegro SM, Miranda P, Mahanty S, et al. (1999): Cytokine production in acuteversus chronic human schistosomiasis mansoni: the cross-regulatory role ofinterferon-_ and interleukin-10 in the responses of peripheral blood mononuclearcells and splenocytes to parasite antigens. J Infect Dis 179: 15021514 . 